\title{
Sustainability of social economy organizations (SEOs): An analysis of the conditions for surviving and thriving
}

\section{Daewook Kim , Wonhyuk Cho \& Barbara Allen}

To cite this article: Daewook Kim , Wonhyuk Cho \& Barbara Allen (2020): Sustainability of social economy organizations (SEOs): An analysis of the conditions for surviving and thriving, The Social Science Journal, DOI: $10.1080 / 03623319.2020 .1799174$

To link to this article: https://doi.org/10.1080/03623319.2020.1799174

曲 Published online: 18 Sep 2020.

Submit your article to this journal $\widetilde{ }$

Q View related articles $\sqsubset$

View Crossmark data $\nearrow$ 


\title{
Sustainability of social economy organizations (SEOs): An analysis of the conditions for surviving and thriving
}

\author{
Daewook Kima, Wonhyuk $\mathrm{Cho}^{\mathrm{b}}$, and Barbara Allen ${ }^{\mathrm{b}}$ \\ ${ }^{a}$ Department of Public Administration, Chonnam National University, Gwangju, South Korea; b'Wellington School of \\ Business and Government, Victoria University of Wellington, Wellington, New Zealand
}

\begin{abstract}
Social economy organizations (SEOs), designed to do good for society, have been attracting significant attention as an alternative to purely profit-driven businesses. However, the sustainability of these hybrid organizations has been questioned due to the challenges in meeting the dual bottom-lines of financial performance and social purpose. This article takes a causal-process tracing (CPT) case study approach and analyzes eight SEOs to investigate the common characteristics of sustainable SEOs. The results of the analysis show that effective leadership is a sufficient (but not necessary) condition for the survival of SEOs, while leadership is a necessary (but not sufficient) condition for SEOs' thriving. Business competitiveness is found to be necessary for SEOs' long-term success and performance over time. Collaborative networking is a contributory condition for SEOs thriving but not a necessary condition for their survival.
\end{abstract}

\section{ARTICLE HISTORY}

Received 11 September 2019

Revised 20 June 2020

Accepted 23 June 2020

\section{KEYWORDS}

Social economy organization; sustainability; social enterprises; third sector

\section{Introduction}

Practical and scholarly interest in the social economy model has risen across many developed economies (Leviton et al., 2006; Spall \& Zetlin, 2004). Many governments have revised their response model for dealing with the market problems of neoliberal economic restructuring, which has inspired the emergence of alternative forms of social innovation (Kim, 2012; Moizer \& Tracey, 2010; Weerawardena et al., 2009). Such forms of social innovation seek to address various social problems by providing services that improve the quality of life of individuals and communities (Allen et al., 2020; Ayob et al., 2016; Pol \& Ville, 2009; Windrum et al., 2016). Local community restoration, urban regeneration, and regional economic promotion are also within the broader scope of the social economy (Barth et al., 2015; D. Kim et al., 2019).

Social Economy Organizations (SEOs) are the core of the social economy movement (LópezArceiz et al., 2016; Visser, 2017), and they represent a commitment to creating social value through employment, welfare, inclusion, and societal integration. Since the late 1980s, SEOs have emerged from two different backgrounds: the non-profit and business sectors. As nonprofit organizations, they have gradually adopted business practices (particularly in their financing models), and as enterprises, they have incorporated social responsibility objectives, which have led to a birth of this hybrid prototype as a distinct category of organizations with market-oriented activities aimed at maintaining the social mission.

Although the development of SEOs has been supported by various international entities and national governments, due to the ability of SEOs to generate both economic and social impact, many SEOs actually have experienced significant challenges in maintaining organizational sustainability and stability. Lack of financial resources and high demand for social action are challenging in terms of meeting the dual bottom line - economic performance and social goals. Despite this challenge, 
many SEOs are surviving and some of them are thriving. Even under pressure to meet financial and social purposes simultaneously, many SEOs still manage to develop innovative strategies, adopt effective management practices, find new opportunities, and diversify their social and economic activities. On the other hand, relatively little is known about the organizational sustainability of SEOs, and there is little understanding of the common characteristics that lead to their success.

The objective of this study is to advance our understanding of SEOs' sustainability conditions and to provide a preliminary analysis for the sustainability of SEOs in achieving both their financial and social goals. We also examine how different mixtures of sustainability conditions act differently on SEOs' economic and social functioning. Several questions guide the analysis: What are the necessary or minimum conditions for the survival of SEOs? What roles are played by leadership effectiveness, business competitiveness, and collaborative networks in maintaining organizational sustainability of SEOs? What are the conditions where SEOs can thrive? These research questions are explored through a qualitative research approach, employing a causal-process tracing (CPT) case study method, which is also known as an outcome-focused or Y-centered case study method. We conducted in-depth interviews with the members of eight SEOs in order to gain qualitative knowledge of the SEOs' sustainability conditions.

\section{Literature review}

\section{Social economy and Social Economy Organizations (SEOs)}

The contemporary model of the social economy first appeared in the 19th century (Chaves \& Monzón, 2011; Visser, 2017). Earlier forms of the social economy model focused more on labour issues, such as ensuring the right to work and implementing solidarity principles. The more recent role of SEOs with a new entrepreneurial spirit focuses on social aims encompassing broader social contribution to the issues faced by the welfare state (Borzaga \& Tortia, 2008).

The social economy model generally refers to the phenomenon associated with economic activities that create social value (Defourny et al., 1999; Defourny \& Nyssens, 2006; Moulaert \& Ailenei, 2005; E. S. Lee \& Suk, 2016), although understandings of the social economy concept differ across countries or regions with varying degrees of usage in policy and political discourse. For example, countries such as Spain, France, Belgium, and Ireland explicitly refer to the social economy as one of their major day-to-day policy approaches, while other European countries merely use the term (López-Arceiz et al., 2017). In the European context in general, the social economy is situated within neo-Keynesianism, specifically as a response to the (re)distribution of wealth, regional autonomy, employment, and sustainable economic growth (Noya \& Clarence, 2007). While in countries in Asia such as South Korea and Hong Kong, the social economy operates much more like a new mechanism for financing social activities (Campbell \& Cho, 2014; H. J. Lee, 2019; Park \& Um, 2010). What various social economy models in different countries have in common is that SEOs are promoted as a strategic tool to correct socioeconomic and regional inequalities and imbalances (Hahn, 2014; Park \& Um, 2010).

Given its relative youth in academic circles, scholarly debate on SEOs has not reached a consensus in regards to agreed-upon definitions (Noya, 2009). There has instead been a terminological proliferation where various terms are used interchangeably; such as social cooperatives, social enterprises, benefit corporations, social impact enterprises, purpose enterprises, community interest companies, and social businesses (W. Lee, 2017; Visser, 2017; Wilburn \& Wilburn, 2014). The SEOs' major activities are also variously referred to as impact investing, social investment, meeting a dual bottom line, investing with purpose, and profit with purpose: dual or double bottom line means that firms can be benefitting society (social bottom line) while earning a profit (economic bottom line) for owners and investors. 
The common denominators in the conceptualization of SEOs and their activities are about pursuing dual (economic and social) missions in their business strategies (Park \& Um, 2010; Powell et al., 2019) - the SEOs' profit is supposed to be directed to finance social activities. With their dual/double bottom line, SEOs follow an evolving business model of bridging the divide between social responsibility and profit margin. The legal forms of SEOs tend to include cooperatives, nonprofit organizations, foundations, associations, social enterprises, community business, and mutual societies (D. K. Kim \& Jeong, 2014; Visser, 2017). However, this classification is adjusted depending on the particular context which the SEOs are operating under - SEOs have different origins and experiences at the regional or national level in regards to economic systems, cultural legacies, welfare structure and legal environment. Theoretically, SEOs are supposed to be independent of public authorities, although there are varying degrees of SEOs' reliance on governmentsourced funds.

By definition, SEOs pursue both economic and social goals, and that is why the traditional categorizations of public, private, or non-profit organizations are not fit-for-purpose (Borzaga \& Tortia, 2007; Lofgren \& Allen, 2019). SEOs are hybrid organizations that bridge the boundaries of sectors or constitute the fourth sector entirely. A social goal connects an SEO's mission to the wider ambition of benefiting the community or society, while an economic goal engages the entrepreneurial nature of the organization to generate profits for investors (López-Arceiz et al., 2016; Visser, 2017). Powell et al. (2019) offer some examples of pursuing dual goals. The Meadow Project runs a tea room, farm shop, bakery and campsite to fund a day service for adults with learning disabilities; the Bluebells is a shop that is used to train service users in retail skills so they are able to sell their own artwork while they ensure the shop has customers to underpin their business goals. These dual goals are not necessarily independent nor mutually exclusive (Prieto et al., 2014), but rather interconnected, while the key idea of the dual bottom line is on maintaining its hybrid nature, explicitly pursuing both goals in their organizational mission.

The hybrid nature of SEOs is embedded in the organizational mission and legal status of those organizations, and there are various types of SEOs depending on the different combinations in the hybrids. For example, López-Arceiz et al. (2016) identified three different hybrid models of SEOs: socially responsible companies, social enterprise, and market-oriented nonprofit, based on the different emphases in those SEOs' mission and activities.

More recently, the contribution of SEOs to local and regional development has attracted considerable attention (D. K. Kim \& Jeong, 2014; Kim \& Lee, 2008). The literature on the social economy has expanded to include urban regeneration, local development, good governance, and cross-sectoral collaborations, and additionally, empirical research has documented diverse linkages between local development and the growth of SEOs in the regions. SEOs have been discussed as more a long-term, rather than a short-term, influence on the socio-economic landscape of a region, thanks to a wider impact than mere profit and its intrinsic contribution to the local economy, regional labour market, and communities (Barraket et al., 2019; Diochon \& Anderson, 2011; Kim \& Cho, 2019; Thompson \& Doherty, 2006; Young \& Lecy, 2014).

Given the context of this study, namely South Korea's social sector, this paper recognizes how the legal and institutional system identifies various types of SEOs in South Korea. Korea's SEOs generally follow the internationally common structures and practices. In South Korea, SEOs for the most part are either a) social enterprises, b) cooperatives, or c) community businesses (Hahn, 2014; D. K. Kim \& Jeong, 2014; Song, 2017).

A social enterprise in South Korea is an organization that has a social purpose and uses corporate assets and wealth for the community's benefit. As of 2019, more than two thousand social enterprises have been established in South Korea and are operated in accordance with the Social Enterprise Promotion Act (2007). Social enterprises have a strong commercial ethos, generating a substantial part of their revenue through business activity, not government subsidy. Any surpluses are thus reinvested either back in the business or in the communities. Social enterprises tend to have more democratic structures with a range of stakeholder involvement. There has been much less focus thus 
far in South Korea on the 'triple bottom line', that combines economic, social and environmental sustainability (C. H. Kim et al., 2013; Im \& Cho, 2008).

A cooperative in South Korea refers to an autonomous organization voluntarily constituted by people who wish to meet their common economic, social, and cultural needs. A cooperative is jointly owned and operated through a democratic decision-making process in the communities. Since the implementation of the Basic Law on Cooperatives in South Korea, there have been over fifteen thousand cooperatives set up, as of 2019. Ownership of cooperatives in South Korea is assigned to a specific category of agents such as consumers, workers, or producers, and they try to improve standards of living in communities.

A community business in South Korea refers to an organization native to a local community or a village, established by local residents to deal with the common problems of their communities through revenue-generating projects (Ministry of Government Administration and Home Affairs, 2016). Like other forms of SEOs, a community business aims at creating sustainable financial resources while contributing to a social purpose. Community businesses, compared to other SEOs, tend to focus more on the employment (or unemployment) issues of the community and have a strong sense of local identity and the cultural values native to the community. Decision making and governance structures are more concerned with the local stakeholders and residents in the regional community or the village. In South Korea, there are more than a thousand community businesses operating as of 2019 .

\section{Sustainability issues of social economy organizations}

Like any other form of organization, not all SEOs survive or thrive. This is not necessarily problematic in the organizational life cycle perspective, since all organizations naturally experience some sort of fluctuation. However, for many academics and practitioners, organizational sustainability has been of great interest in order to learn how we can prevent organizations from declining or failing (Choi \& Lee, 2015).

Organizational sustainability has also been conceptualized in various ways, but generally, it is involved with success and failure as an organization. For example, organizational sustainability is defined as 'keep the business going' (Colbert \& Kurucz, 2007) or 'future-proofing' of organizations (Wales, 2013), or 'achieving success today without compromising the needs of the future' (Boudreau \& Ramstad, 2005). Different conceptualizations of organizational sustainability emphasize different aspects of organizational success or failure; such as resource acquisition, efficiency in management, effectiveness in accomplishing an organizational mission, and economic performance (Helmig et al., 2014; Kim, 2012). Death or disappearance often equates to organizational failure but this is not always the case. Highly successful organizations sometimes discontinue operation for various reasons. In this respect, organizational sustainability and organizational success/failure can be regarded as different dimensions. On the other hand, several definitions of organizational sustainability do emphasize success, not just mere survival, when they consider how an organization can keep the business going in the future (Wales, 2013). For example, an organization can compromise the longer-term sustainability of the business for survival in the short-term making it difficult to categorize them as a sustainable organization.

Among the many meanings of organizational sustainability, this study focuses on meeting the dual bottom line (financial performance and social impact), because organizational sustainability poses particular issues for SEOs. SEOs are supposed to generate revenue through market-based activity in their self-sustaining purpose, while, on the other hand, continued social action and activity are also important aspects of their organizational mission, and the justification or legitimacy of their existence. Also in the (multi)stakeholder perspective, SEOs have dual goals because there are stakeholders whose concerns lie primarily with the SEOs' economic performance, while there are other stakeholders who care much more about generating social impact (López-Arceiz et al., 2016). 
Analysis of the organizational sustainability of SEOs is timely and relevant since many SEOs in different nations have sustainability issues, such as unstable access to financial resources, a low degree of recognition about their social activities, and lack of entrepreneurial and managerial capacity. SEOs struggle to secure funding opportunities because they are usually small in size, and customers or stakeholders do not fully understand how SEOs operate. Awareness about SEOs is a significant issue for maintaining sustainable operations for both their social actions and generating economic wealth.

\section{Sustainability conditions for SEOs: Analytical framework}

This study focuses on organizational sustainability as the desired outcome for SEOs, and how there can be numerous conditions and factors associated with this. A considerable number of studies have explored these issues, and as such we have devised an analytical framework for examining these sustainability conditions by integrating the main points of organizational sustainability theories. Based on our literature review on this topic, we intend to narrow the scope of our analysis into managerial and internal aspects that may influence the organizational sustainability of SEOs.

We have formulated an analytical lens for examining the sustainability of SEOs based on three themes from the literature: effective leadership, business competition, and collaborative networks. These conditions have been recognized in previous studies as important in diversifying organizations' funding base while expanding their operating budget. Helmig et al. (2014) conducted a review of the success and failure of nonprofit organizations and they emphasized human resources, leadership, governance, marketing activities, and market competitiveness. Other studies such as that of Wheeler et al. (2003) noted the significance of entrepreneurship and corporate management skill, and partnerships. Sharir and Lerner (2006) emphasize social networks, commitment to organizational mission, business innovation, and managerial experiences of entrepreneurs. Choi and Lee (2015) stress new business models in facilitating financial performance and the role of managers, and stakeholder networks of social enterprises.

In our study, we recognize the variables that have been explored in the literature and narrow the scope to themes that are both derived from the literature and hold salience within the South Korean context. Research on SEOs in South Korea has expanded particularly in the 2010s and it has explored various issues that SEOs are facing such as community networks (H. J. Lee, 2019; Y. Lee \& Lee, 2017), leadership (Oh, 2013), innovation (Song, 2017), social capital (D. K. Kim \& Jeong, 2014), social exclusion (Hahn, 2014), and challenges in meeting the double bottom line (Park \& Um, 2010). From our analysis of the literature, we found that effective leadership, business competitiveness, and collaborative networks are elements that are relevant to South Korea's context and can lead to findings that may inform both practitioners and academics. Further, the selected dimensions are reasonably mutually exclusive, which is critical in this kind of analysis, although we acknowledge that these aspects of SEOs can interact with each other.

In regard to leadership effectiveness, Noya (2009) emphasizes the importance of the founder's character in terms of his or her operational skills and socially-oriented mindset. Weppen and Cochrane (2012) stress that strong leadership is one of the most important success factors, and pointed out the necessity of the leader having both appropriate social awareness and experience in corporate management. Chang et al. (2012) emphasize the importance of the personal characteristics of the leader(s), whereas Choi (2013) highlighted the CEO's management skills and experience. In this study, we focus more on leaders' management skills, rather than leadership traits, so that we can draw out the implications for developing such skills and experiences.

Business competitiveness is associated with the development of new business models to generate stable revenue in the market. Studies highlight the quality of goods and services and the strength of market competitiveness as important conditions for SEOs. Sharir and Lerner (2006) emphasizes the ability to survive in the market, and Weerawardena et al. (2009) suggest 
organizations need to build an entrepreneurial strategy. Weppen and Cochrane (2012) stress the importance of a clear market orientation.

Collaborative networks involve the networking activities that occur with the various stakeholders and other organizations to achieve the mission of SEOs. Studies have suggested that networks with various stakeholders enable social support and cooperation. Noya (2009) emphasized the importance of exchanging both necessary information and advice between SEOs through appropriate networks. Still, little is known about how networking plays a role in being a self-sustaining mechanism for SEOs.

\section{Method}

\section{Research approach}

This study employs the causal-process tracing (CPT) approach for case studies since the aim of this research is to understand a specific kind of outcome - gauging and enhancing the organizational sustainability of SEOs. Research often aims at examining whether a certain condition is a cause of a particular outcome in a specific case, and this is why CPT has recently emerged as one of the most widely used, and arguably most important, causal inference methods in case study design, either as a standalone technique or as a complement to other methods (Collier et al., 2010). CPT research seeks to answer the question 'Was $X$ a cause of $Y$ in case $Z$ ?' and explores a general causal effect in particular cases (Mahoney, 2012). CPT analysis makes causal inferences by the causal-process observation that looks at diagnostic pieces of evidence that have probative value in testing hypotheses (Collier et al., 2010). Generally, researchers use causal-process observations with broader generalizations relevant to the analyzed case(s).

There are variants in CPT approaches depending on different research purposes (Kay \& Baker, 2015). The case-centric CPT is used for a mechanistic explanation of outcomes of a particular case, and this is often applied to a very unique and complex case where its context cannot be easily generalized (Beach \& Pedersen, 2019). The theory-centric CPT is employed to deductively test existing theory from literature and examine whether a causal mechanism hypothesized by the theory is absent or present in the selected case(s). The theory-building CPT is aimed at developing a new theory about causal mechanisms based on the selected cases, which is often used when an outcome (Y) is known but it is uncertain what causes it (X) (Kay \& Baker, 2015). In this article, we take the theory-centric CPT approach for our research methodology, therefore, we deduct theories from the literature on what causes organizational sustainability of SEOs and examine whether those causal mechanisms are present or not in SEOs we selected.

As we outlined in the literature on this topic, there are various causes of organizational outcomes, but we focus on the result of these causes, and this is why we can also consider this as Y-centered research. We assume that various conditions work together to lead to the outcome, and we search for configurations of such causal mechanisms to understand the pathways to the sustainability of SEOs. We ask which conditions are necessary or sufficient or contributory to lead this outcome of interest.

Based on the methodological suggestion by Befani and Mayne (2014), we combine CPT and contribution analysis in generative causal inference. Contribution analysis emerged in the field of evaluation studies, while CPT came out of case study design. Contribution analysis postulates a theory of change (ToC) for the interventions or the conditions that are being examined by evidence available. The idea of combining CPT with contribution analysis is from a notion that an intervention is unlikely to be the sole cause of a subsequent change, and often it is rather a contributory cause, therefore, we expect not just a causal relationship but also other contributory condition(s) together would form a sufficient cause for an outcome of interest. In this regard, Befani (2013) discussed in detail contributory causes that are not either sufficient or necessary to bring about the desired change. In the contribution analysis, there is a SUIN (Sufficient but Unnecessary part of an Insufficient but Necessary disjunction) and there is an INUS (Insufficient 
but Necessary part of an Unnecessary but Sufficient conjunction). Contribution analysis suggests that it is reasonable to conclude that the intervention in question has made a difference if an analysis can verify the theories of change with empirical evidence, and applying causal process tracing perspective can strengthen the contribution analysis in generative causal inference (Befani \& Mayne, 2014).

In the CPT approach or Y-centered case study, generalization of the findings means a 'possibilistic' generalization (Gerring \& Cojocaru, 2016; Kim \& Cho, 2019; Yin, 2012). The findings lead to knowledge about the causal configurations, or combinations, of causal conditions that make the outcome of interest possible. The potential configuration is useful for developing typological theories, while the proven configuration is helpful in identifying all conditions that have been proven to lead to the outcome.

In the causal-process tracing, researchers selected cases that show a strong positive result in regards to the outcome of interest. With this Y-centered approach, empirical information about the causal-process is often collected in an inductive process, and the separation between data collection and data analysis can be less clear-cut (Blatter \& Haverland, 2012a). The empirical information is then combined with theoretical reflection on causal mechanisms for analyzing the configurations of conditions that are either individually necessary or jointly sufficient for the outcome.

For this study, we selected eight SEOs in South Korea that were awarded excellence awards by the South Korean government. This method to select award-winners has been widely used in various case studies in different fields such as organizational research, business studies, quality management, education policy, and journalism research (Abdullah, 2010; Blackburn \& Rosen, 1993; H. H. Lee \& Li, 2015; Ingelsson et al., 2012; Di Serio et al., 2011; Virakul et al., 2009; Wahl-Jorgensen, 2013). For example, Blackburn and Rosen (1993) selected Baldrige Award-winning companies for their analysis and found that human resources management supports a total quality culture of those firms, and Di Serio et al. (2011) analyzed PNQ National Quality Award-winning firms to study factors associated with risk management practices.

The justification for our study's case selection is that the assessment tools used for these awards by the South Korean government were all focused on the outcomes of interest for this study, namely economic performance and social impact. The award criteria reflect the dual bottom lines of benefitting society while earning a profit for owners and investors. They also closely follow decision making to hold SEOs more accountable for achieving both social and financial goals. The assessment committees for the awards, who are experts in South Korean SEOs, use quantitative and qualitative criteria in assessing the dual bottom lines. And then the assessment results are reviewed by relevant central government ministries and related agencies, including the Ministry of Economy and Finance, the Ministry of Government Administration and Home Affairs, and the Korea Social Enterprise Promotion Agency. Among the awarded organizations, random extraction was conducted (Rutzen et al., 2004).

Another criterion for case selection was the accessibility and reliability of the data collection processes (Blatter \& Haverland, 2012b). Given that the goal of a case study is to create knowledge beyond what can be understood through large sample research, access to information on things that are not easily measured is critical. Data collected needs to provide comprehensive evidence on the causal process, in order to provide a description of critical information. Therefore, data availability was also a crucial criterion. Further, we selected cases that are independent of each other in order to provide causal conclusions.

Although this research is a Y-centered small N case study, we also considered the representativeness in our case selection processes. Representativeness of the cases is a common concern in case studies, and we chose cases considering the presumed representativeness. That is why we use diverse cases (three different types of SEOs) so that the selected cases are expected to be representative of a subset of the population. The selected SEOs differ in their locations, purposes of establishment, business models, and membership. We chose a diverse-case approach to case-selection and we iterated representative-case procedures among the sub-populations. 
Up to three cases of SEOs were selected for each type of SEOs, all of which remain active. Indepth interviews (onsite, in-person, and one-to-one) were conducted with representatives and staff members from each organization. The semi-structured interview questions were based on the elements of the analytical framework; however, open-ended questions were also used, in that we wanted the interviews to be emergent as well. This strategy allowed us to hear the interviewees' diverse and unconstrained opinions about the sustainability of SEOs. We also integrated observational evidence into our analysis.

We tested hypothesized causal mechanisms with commonly used methods of 'hoop tests' and 'smoking gun tests' suggested by Van Evera (1997) and Collier (2011). These tests draw on information concerning mechanisms as a basis for causal inference (Collier, 2011; Van Evera, 1997). Although the tests are usually not carried out explicitly, they are often used implicitly by analysts working on comparative case study research. A hoop test identifies a condition whose presence is necessary for the hypothesis to be accepted as true and failure to pass a hoop test means that the hypothesis is eliminated. Therefore a hoop test is useful to see necessary (but not sufficient) conditions of the outcome of interest (Bennett, 2004). Smoking gun test, on the other hand, is useful to test sufficient (but not necessary) conditions for the outcome (Collier, 2011), although this test can be also used for testing necessary conditions in some cases, and passing a smoking gun test means the existence of the causal mechanism. Failure to pass a smoking gun test does not eliminate the possibility of an outcome to exist. A smoking gun test for finding sufficient conditions is very commonly used by detectives or medical examiners, but in social science research, smoking gun tests are used to develop arguments about mechanisms that are sufficient for the occurrence of an outcome of interest (Bennett, 2004; Bennett et al., 2019).

\section{Research context and cases selected for analysis}

The context where this research was done is the institutional environment of SEOs in South Korea. The South Korean government is promoting SEOs to restore its regional communities, revitalize local economies, fill the gaps in social services, and provide sustainable regional development. However, relatively few cases of self-sufficiency have been reported. Problems such as the lack of appropriate business models and insufficient organizational capacity create great challenges for SEOs in the country (Choi \& Lee, 2015; Park \& Um, 2010), although they try to diversify funding streams to make their organizations self-sustaining.

For the representativeness in our case selection processes, we use a diverse case approach, drawing social enterprises, cooperatives, and community businesses as the representative types of SEOs based on previous research done in South Korea's third or fourth sector (H. J. Lee, 2019; Oh, 2013; Park \& Um, 2010; E. S. Lee \& Suk, 2016; Song, 2017), ${ }^{1}$ which is also consistent with international literature. Before analyzing the cases in depth, we briefly examined the relevant organizations. The specific framework elements applied to each organization vary according to the organization's characteristics since as shown in Table 1, the specific analysis targets included Songdo SE (Case A), Happy Narae (Case B), Junglip Electronics (Case C), Babyra (Case D), Wezon (Case E), Red Ribbon (Case F), Pyeonajio (Case G), and Cultural Playground in Dream (Case H).

\section{Social enterprises}

Social enterprise Songdo SE (Case A), located in the city of Incheon, was launched in 2010. It has 1.3 billion won in capital and is an example of the self-reliant social enterprises set up by Pohang Iron \& Steel Company (POSCO) to provide reliable employment opportunities to vulnerable sections of the community. Its main businesses include beautification of buildings, parking

\footnotetext{
${ }^{1}$ This typology is originally from legal terms in South Korea's social economy system and is commonly used among scholars and practitioners. The three types of SEOs are not mutually exclusive. For example, a social enterprise can have legal status as a cooperative too.
} 
Table 1. Selected cases by type of social economy organization.

\begin{tabular}{lll}
\hline Type & \multicolumn{1}{c}{ Subject Name } & \multicolumn{1}{c}{ Award Received } \\
\hline Social Enterprise & Case A: Songdo SE & 2014 Ministry of Employment and Labor's Award \\
& Case B: Happy Narae & 2014 President's Award \\
& Case C: Junglip Electronics & 2014 Prime Minister's Award \\
Cooperative & Case D: Babyra & 2015 Best Practices for the Co-operation of the Ministry of Strategy and \\
& & Finance \\
& Case E: Wezon & 2016 Deputy Prime Minister's Award \\
& Case F: Red Ribbon & 2015 Best Practices for the Co-operation of the Ministry of Strategy and \\
Community & Case G: Pyeonajio & Finance \\
Business & & 2014 Superior Community Business of the Ministry of Security and Public \\
& Case H: Cultural Playground in & Administration \\
& Dream & 2014 Superior Community Business of the Ministry of Security and Public \\
& & Administration \\
\hline
\end{tabular}

management, office support, and the operation of multicultural cafés. Songdo SE was awarded the Minister of Employment and Labor's Award in 2014.

Happy Narae (Case B), located in Jung-gu, Seoul, was established in 2000 and certified as a social enterprise in 2013. It has 8 billion won in capital and is supported by the conglomerate SK Hynix. Sourcing and procuring industrial materials and consumable materials is Happy Narae's focus. The company acts as an intermediary in the purchase and delivery of goods from social to large enterprises. It was awarded the President's Award in 2014.

Junglip Electronics (Case C), located in Gwangjin-gu, Seoul, is a vocational rehabilitation facility for people with disabilities; it was established in 1989. The Korea Small and Medium Business Association, a social welfare agency, operates Junglip Electronics, which manufactures and sells electric and electronic products, such as light-emitting diode lights, computers, closed-circuit television systems and electric signboards, and small information technology (IT) products. Junglip Electronics was awarded the Prime Minister's Award in 2014.

\section{Cooperatives}

Babyra (Case D), located in Songpa-gu, Seoul, was founded in 2013. Previously, it existed as a business partner, supplier, and agent of another company; however, following the bankruptcy of the other company, Babyra was established as an independent enterprise. Its business involves the joint production and sale of infant clothing and products. Babyra was cited in the Ministry of Strategy and Finance's best practices for cooperatives in 2015.

The cooperative Wezon (Case E), based in Daejeon, was established in 2012. It provides IT solutions tailored to suit SEOs in the region, develops solutions to improve information accessibility, and produces homepages, shopping malls, and mobile applications. Wezon was awarded the Deputy Prime Minister's Award in 2016.

Red Ribbon (Case F), located in Daegu City, was founded in 2010. It operates Big Hands Café. Established to support people with Acquired Immunodeficiency Syndrome (AIDS), Red Ribbon sells coffee and beverages in collaboration with those afflicted by the disease. Red Ribbon also produces and sells items which share the stories of people with AIDS. It was cited by the Ministry of Strategy and Finance for its best practices for cooperatives in 2015.

\section{Community businesses}

Pyeonajio (Case G), based in Daegu, is a community business that was established in 2013. Its business is the production and sale of handmade shoes. In the 1970s and 1980s, Daegu's handmadeshoe industry, in which 130 companies had been active, collapsed with the advent of cheap Chinese shoes. Pyeonajio was established to salvage the situation at a time when approximately 50 handmade-shoe companies remained productive. In 2014, Pyeonajio was selected as the Superior Community Business of the Ministry of Security and Public Administration. 
The community business Cultural Playground in Dream (Case H) was established in 2013. It was created by ten young people engaged in the promotion of cultural arts (planning, designing, and executing performances, and educating others about arts) in the region. Efforts are focused on nurturing cultural and artistic skills and offerings include local festivals, performances, educational programs, and village projects. In 2014, Cultural Playground in Dream was selected as the Superior Community Business of the Ministry of Security and Public Administration.

\section{Results of analysis}

In our interview process and subsequent qualitative data analysis, we found that there are within-sample variations in the outcome of our interest, organizational sustainability, and the conditions drawn from the literature play different roles. Therefore, we distinguished between 'surviving' and 'thriving' as our outcomes of interest and analyzed how leadership effectiveness, business competitiveness, and collaborative networks are associated with each of these two. Figure 1 presents the difference between thriving and surviving, drawn from both our interview data and literature on dual bottom lines of SEOs. Researchers based this categorization of performance levels (bottom line vs success line) on our coding process of the interview transcripts: we used consistent methods in this process following previous works using the case study approach with interview data such as H. H. Lee and Li (2015), Virakul et al. (2009), Di Serio et al. (2011), and Blackburn and Rosen (1993).

\section{Leadership effectiveness}

We found that effective leadership is a sufficient condition for SEO's organization's survival, as it is found to be a common characteristic observed in most of the selected cases. Often, the social and business activities of SEOs do not seem to reinforce each other, and leaders are found to be a core agent who makes important decisions that affect the SEOs strategic direction. This role is particularly critical because the two different missions of economic and social objectives may compete with each other for resources when both sides have equally legitimate justifications. We found that the leaders in the selected SEOs understand the

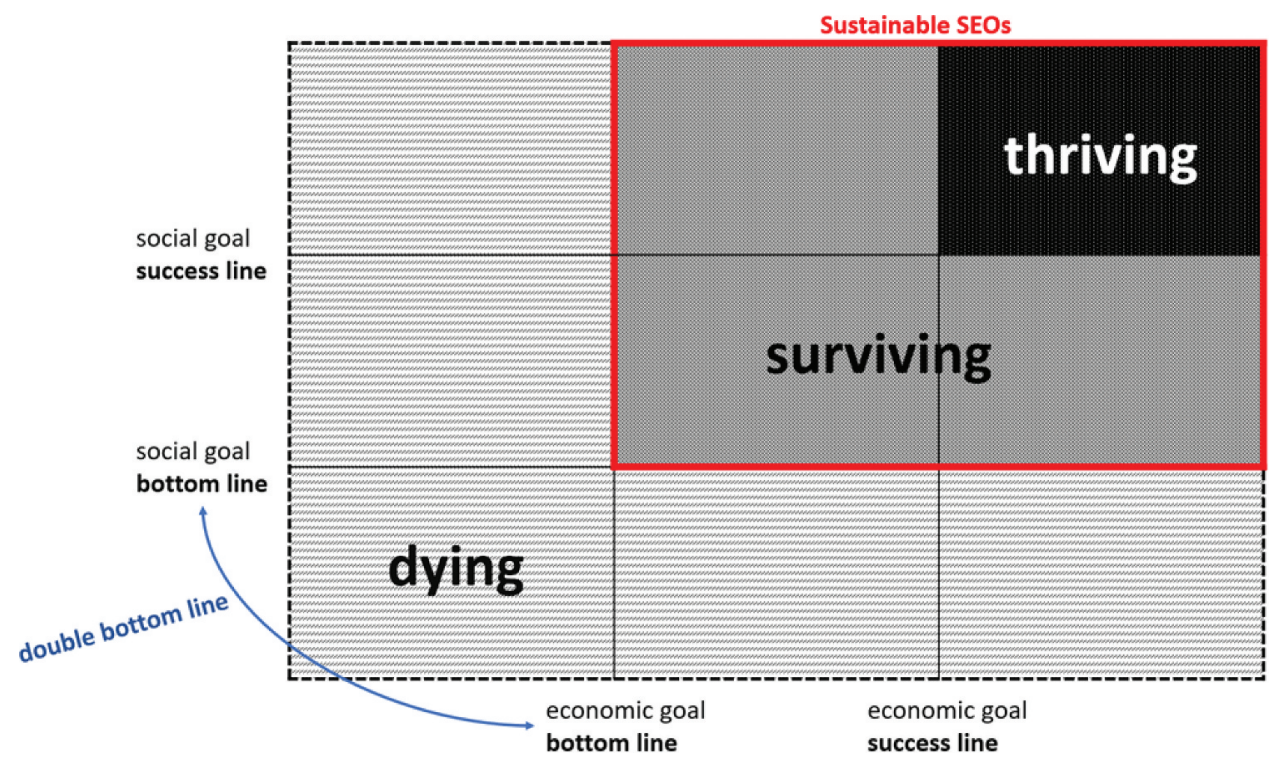

Figure 1. Double Bottom Line of Sustainable SEOs. 
dual missions of the organizations, and they contribute to proactive rather than reactive decisions on the use of resources between reinvestment in the business and an investment in social functions, which were later proven to be crucial in sustaining SEOs. Facing a limited availability of resources, the leaders of the selected cases showed their ability to efficiently integrate and reconfigure resources. Although the leaders were at the centre of important strategic decision-making, their decision-making styles were found to encourage the participation of all staff and stakeholders. For example, at Junglip Electronics (Case C), the leader did not dictate all decisions but established a very participatory and flexible decision-making system where all staff members were made aware of the company's current situation, and many decisions were made through effective delegation to department heads and middle managers. The leader's efforts to create participatory and transparent decision-making procedures were also observed in the case of Wezon (Case E) and in the case of the Cultural Playground in Dream (Case H).

Effective leadership is found to play a crucial role in managing people in SEOs. SEOs are often small in size and sometimes have a limited number of salaried employees. Salaried employees and leaders often need volunteers (i.e. unpaid) for their operation. Case study leaders were effective in fore-fronting the mission and core values of their SEOs among employees, helping to draw volunteers. Effective leadership is found to be crucial in clarifying the responsibilities of different staff, sharing and communicating critical information in a timely manner, resolving conflicts inside and out, and inspiring followers for the organizational mission. For example, in Babyra (Case D), an effective communication system was facilitated by the leaders so that they could brainstorm on a regular basis about innovative resolutions to issues such as digitalization of the café operation, managing supply chains, and accounting complexities.

SEOs are often understaffed and existing staff are also often underpaid, but they are still expected to perform multiple functions. We found that effective leadership is crucial in making things more efficient without causing staff burnout. For example, at Songdo SE (Case A), the leader showed an exceptional ability to recruit or head-hunt the most qualified, experienced, and motivated staff so that the organization could operate efficiently. Passion-led burnout is found to be prevalent in SEOs, and effective leaders have played an important role in ensuring that their staff can be resilient. For example, in the case of Wezon (Case E), the company's mission and purpose were communicated skillfully by its leaders, and all staff were found to closely share the social values of the organizations. This was also found in Red Ribbon (Case F), and in the case of the Cultural Playground in Dream (Case H).

Effective leadership also plays an important role in creating collaborative networks with relevant groups of stakeholders, which is another important condition for sustainability. Effective leaders build mutually reciprocal relationships in cross-sectoral partnering. We found that effective leadership in the selected SEOs succeeded in creating networking that led to more and better business opportunities in obtaining resources, as well as improving the quality of social activities. For example, at Happy Narae (Case B), its leader displayed strong skills in networking, and this enhanced the company's external status and brand value significantly, which in turn contributed to organizational sustainability.

Effective leadership is also important in compensating for the overall insufficiency in managerial capacity of SEOs. The selected SEOs tended to lack professional training or qualifications, and we found that the leaders in the selected SEOs made considerable efforts to develop professionalism in the workplace, while allocating resources to staff training. These efforts in turn contributed to the sustainability of the SEOs.

However, with respect to SEOs' thriving not just surviving, leadership effectiveness is not a sufficient but necessary condition. This means that without effective leadership (necessary cause), SEOs cannot thrive, but it does not ensure SEOs' thriving: leadership effectiveness is not sufficient.

\section{Business competitiveness}

From our collected interview data and causal processing inference, we found that business competitiveness was a sufficient but not necessary condition to the SEOs' thriving, which is associated with 
long-term success, but this was not a necessary condition for SEOs surviving either. We found that business competitiveness is a common characteristic of SEOs that are thriving, rather than merely surviving. For example, among selected SEOs, the three cooperatives were not necessarily competitive in their markets, but they managed to survive and function as SEOs.

We found that the SEOs with strong market orientations achieved not just higher revenue but also better social outcomes. The SEOs with business competitiveness showed fewer financial stresses, which in turn made things easier also for their social actions. Business competitiveness in SEOs' goods and/or services contributed to higher performance in social goals as well, without distorting the core values of their organizations. This creates a virtuous circle of increasing the levels of economic and social performance. The business competitiveness of SEOs led to capital accumulation, and then this resource was reinvested for the greater success of SEOs' dual mission, which in turn led to stronger organizational competencies. For example, Pyeonajio (Case G) was certified as a 'Korean Name' based on its ability to produce high-quality handmade shoes, and appearances in the South Korean media have helped increase its sales revenue, which led to enhanced economic and social success. Junglip Electronics (Case C) is another example of a virtuous circle. They reinvested in production facilities and quality management which increased their market competitiveness, which led to stable consumption in the market as well as by government offices.

The SEOs that did not present sufficient business competitiveness still managed to survive, but they did not grow financially and tended to rely on purchase or procurement by the government, or a limited number of donors, such as business conglomerates or community consumption. Our analysis also shows that organizational sustainability does not necessarily mean organizational success. We found that some SEOs tend to be concerned about committing too much on the business side of the organization and less about social goals, and eventually losing their legitimacy as SEOs among stakeholders. This may mean that these SEOs are still trying to balance the dual bottom line in their own way. Further, some of the SEOs did not intend to grow (and possibly change their nature of organizations), but rather merely maintain their existing size and function, which they perceive as helping to achieve their organizational purpose. The cooperatives selected for this study have strong consumption by community and members of the cooperatives, therefore they did not appear to grow to a scale that is not manageable within the community. Babyra (Case D) is a representative example of this inclination. Babyra has strong consumption by the community in their infant and toddler clothing sales, and their primary concern is to benefit the members of the cooperative with profit, provide a labour-friendly environment, and produce affordable clothing in the community. They are not entirely indifferent to the growth of the business, but that is not their primary concern. Their concept is that social action can lead to legitimacy for them in the eyes of the community that they serve, and that legitimacy is the core for their survival as a business because that drives the consumption of their product within the community.

\section{Collaborative network}

We found that collaborative networks are a contributory cause of SEOs' thriving, particularly in amplifying the social impact of SEOs. The SEOs selected proactively participate in collaborative networks, and their social activities were well-supported by stakeholders. The form of the collaborative networks tends to be informal, such as casually coordinating and working together in social action or exchanging information and resources. Some SEOs participated in formal collaboration activities, via such things as formal agreements and service contracts.

We found that the SEOs exchange their technology, assets, experience, and resources through collaborative networks, and they were able to serve larger groups more efficiently as a result. For example, Wezon (Case E) is proactively participating in a network of social enterprises in the Daejeon area. The leader is an executive member of the association 
known as the Social Enterprise Council, which encourages an active information exchange and performs business activities. Further, when they organized activities or events for their social goals, the collaborative network is found to play a significant role. For example, Junglip Electronics (Case C) used their collaborative network to bridge socially vulnerable groups and business suppliers to diffuse their social innovation model to the wider industry.

The collaborative network of SEOs is found to be useful in developing cross-sectoral partnerships among private, public, and nonprofit entities, particularly in creating their community-oriented social value chain. The SEOs were able to receive and share important resources and capacities for their core functions through the network. Many SEOs are small in size, but these activities require resources that may be common to many of them, therefore collaborative efforts in the cross-sectoral network can employ the benefits from an economy of scale in their social activities. Awareness of the social cause of the SEOs is another critical aspect of achieving their goals and encouraging participation from community members and stakeholders, and collaborative networks played a critical role in increasing the level of such awareness. For example, Cultural Playground in Dream (Case $\mathrm{H}$ ) built a network with their service target groups, such as its surrounding communities and the residents of local communities. They also expended significant effort to maintain friendly relations with intermediary support organizations.

\section{Cross-case synthesis}

As described in the previous section, the key outcome of interest in this study is organizational sustainability. The result of the CPT analysis is summarized in Table 2. Using empirical information from our interview data as a basis for causal inference, we employed the 'hoop test' and 'smoking gun test' to provide cross-case synthesis about the causal mechanisms. We found the causal configurations concerning leadership effectiveness, business competitiveness, and collaborative networks: leadership effectiveness is found to be a sufficient and necessary condition for SEOs' survival but not a sufficient condition for SEOs' thriving and long-term success. Business competitiveness is not a sufficient nor necessary condition for survival of SEOs but it is necessary for SEOs to thrive. Business competitiveness is a common characteristic of SEOs that are thriving instead of merely surviving. We found that collaborative networks contribute to the social impact of SEO activities, but with respect to conditional configuration, the result of analysis is inconclusive because we do not have enough evidence from about half of the selected SEOs as to their networking activities. In other words, a collaborative network is SUIN (sufficient but unnecessary part of an insufficient but necessary disjunction) condition for SEOs' thriving. Therefore, the causal configuration of this study reveals that different combinations of effective leadership, business competitiveness, and collaborative networks form different conditions for SEOs to survive or thrive.

Table 2. Results of analysis: Cross-case synthesis.

\begin{tabular}{lcccc}
\hline Case & $\begin{array}{c}\text { Leadership Factors } \\
(\mathrm{X} 1)\end{array}$ & $\begin{array}{c}\text { Business Factors } \\
(\mathrm{X} 2)\end{array}$ & $\begin{array}{c}\text { Network Factors } \\
(\mathrm{X} 3)\end{array}$ & $\begin{array}{c}\text { Sustainability Outcome } \\
(\mathrm{Y})\end{array}$ \\
\hline A & $O$ & 0 & $\mathrm{n} / \mathrm{a}$ & Surviving \\
B & $O$ & 0 & 0 & Thriving \\
C & $O$ & 0 & 0 & Thriving \\
D & $O$ & $\times$ & $n / a$ & Surviving \\
E & $O$ & $\Delta$ & 0 & Surviving \\
F & $O$ & $\Delta$ & n/a & Surviving \\
G & n/a & $O$ & n/a & Surviving \\
H & $O$ & $O$ & 0 & Thriving \\
\hline
\end{tabular}

Note: $\bigcirc$ : exemplary, $\Delta$ : satisfactory, $\times$ : unsatisfactory, n/a: not applicable (information not available) 
This result means that without effective leadership, SEOs cannot thrive, though they may survive. SEOs may survive without business competitiveness if they have strong consumption by certain community groups or strong procurement favours by government or parent organizations. Collaborative networking is found to be not a necessary condition for SEOs' survival although it is a contributory condition for thriving SEOs. In this regard, some SEOs may even refuse to grow in business competitiveness and/or the scale of their enterprises in order to maintain their particular social goals. Therefore, our finding does not suggest one best way or one desired set of strategies but implies possible tension between the dual goals of SEOs. On the other hand, we also found that strong market competitiveness can create a virtuous circle that enables SEOs to reinvest in their economic and social function, and will lead to better performance in both goals.

\section{Conclusions}

The objective of this article is to analyze the conditions that allow SEOs to survive and thrive in their financial and social purposes. The results obtained in this study reveal that leadership effectiveness, business competitiveness, and collaborative networks are important conditions for SEOs' organizational sustainability, but each of them works differently in how they contribute to the sustainability outcome.

Although this study takes a case study approach, the relatively small sample size places limits on the ability to generalize the findings, and our interview data has incomplete information about the core condition of our interest. Nonetheless, this study represents a preliminary look at how SEOs can make their organizations self-sustaining. Our analysis shows that a strong role for leaders is a common characteristic of our selected SEOs, and business competitiveness is an important condition for a virtuous circle to create a reinvestment loop in the social and economic activities of SEOs. This study demonstrates that collaborative networking is contributing to SEOs' thriving, particularly in their social actions.

This study has both theoretical and practical contributions. From an academic perspective, this study further informs the underlying conditions that surround the sustainability of SEOs. Both the literature and the case studies confirm the classification of the conditions that influence SEOs as: leadership effectiveness, business competitiveness, and collaborative networks. These categories can form an analytical framework for future empirical (covariation) research with larger samples and thus further contribute to understanding the sustainability of SEOs.

From a practical perspective, the study's contributions include proposals for organizational improvement strategies, as well as governmental policy support strategies, to promote the sustainability of SEOs. This study also provides a sound reference for future social innovation programs in the field, as well as a basis for the examination of the effect of any government-led programming that supports the activities of SEOs.

Future studies can explore more with respect to the institutional factors that are outside of the research scope of this study. Institutional factors are related to the relevant legislation; to the government; and to the support system. Many governments are preparing legislation related to social innovation strategies targeting SEOs.

\section{Highlights}

- Effective leadership is necessary for SEOs thriving beyond their mere survival.

- Well-designed networking strategies for collaboration are a contributory condition for achieving success in social goals of SEOs' activities

- Business competitiveness is not a sufficient nor necessary condition for survival of SEOs but it is necessary for SEOs to thrive. 


\section{References}

Abdullah, A. (2010). Measuring TQM implementation: A case study of Malaysian SMEs. Measuring Business Excellence, 14(3), 3-15. https://doi.org/10.1108/13683041011074173

Allen, B., Tamindael, L. E., Bickerton, S. H., \& Cho, W. (2020). Does citizen coproduction lead to better urban services in smart cities projects? An empirical study on e-participation in a mobile big data platform. Government Information Quarterly, 37(1), 101412. https://doi.org/10.1016/j.giq.2019.101412

Ayob, N., Teasdale, S., \& Fagan, K. (2016). How social innovation 'came to be': Tracing the evolution of a contested concept. Journal of Social Policy, 45(4), 635-653. https://doi.org/10.1017/S004727941600009X

Barraket, J., Eversole, R., Luke, B., \& Barth, S. (2019). Resourcefulness of locally-oriented social enterprises: Implications for rural community development. Journal of Rural Studies, 70, 188-197. https://doi.org/10.1016/j. jrurstud.2017.12.031

Barth, S., Barraket, J., Luke, B., \& McLaughlin, J. (2015). Acquaintance or partner? Social economy organizations, institutional logics and regional development in Australia. Entrepreneurship \& Regional Development, 27(3-4), 219-254. https://doi.org/10.1080/08985626.2015.1030458

Beach, D., \& Pedersen, R. B. (2019). Process-tracing methods: Foundations and guidelines. University of Michigan Press.

Befani, B. (2013). Multiple pathways to policy impact: Testing an uptake theory with QCA. CDI Practice Paper 5. Brighton/United Kingdom: IDS

Befani, B., \& Mayne, J. (2014). Process tracing and contribution analysis: A combined approach to generative causal inference for impact evaluation. IDS Bulletin, 45(6), 17-36. https://doi.org/10.1111/1759-5436.12110

Bennett, A. (2004). Case study methods: Design, use, and comparative advantages. In D. F. Sprinz \& Y. WolinskyNahmias (Eds.), Models, numbers, and cases: Methods for studying international relations (pp. 19-55). The University of Michigan Press.

Bennett, A., Fairfield, T., \& Soifer, H. D. (2019). Comparative methods and process pracing. American Political Science Association Organized Section for Qualitative and Multi-Method Research, Qualitative Transparency Deliberations. Working Group Final Reports, Report III.1. http://dx.doi.org/10.2139/ssrn.3333405

Blackburn, R., \& Rosen, B. (1993). Total quality and human resources management: Lessons learned from Baldrige Award-winning companies. Academy of Management Perspectives, 7(3), 49-66. https://doi.org/10.5465/ame.1993. 9411302347

Blatter, J., \& Haverland, M. (2012a). Designing case studies: Explanatory approaches in small- $N$ research. Palgrave Macmillan.

Blatter, J., \& Haverland, M. (2012b). Two or three approaches to explanatory case study research? Annual Meeting of the American Political Science Association, 8-10.

Borzaga, C., \& Tortia, E. (2007). The social economy. In A. Noya \& E. Clarence (Eds.), Social economy organizations in theory of the firm (pp. 23-60). OECD.

Borzaga, C. \& E. Tortia. (2008). Social economy organisations in the theory of the firm. In Noya, A. and E. Clarence (Eds.), The social economy: Building inclusive economies, OECD Publishing. https://doi.org/10.1787/97892640398893-en

Boudreau, J. W., \& Ramstad, P. M. (2005). Talentship, talent segmentation, and sustainability: A new HR decision science paradigm for a new strategy definition. Human Resource Management, 44(2), 129. https://doi.org/10.1002/ hrm.20054

Campbell, J. W., \& Cho, W. (2014). Two faces of government-business relations during South Korea's developmental period. Korean Comparative Government Review, 18(1), 47-66. https://doi.org/10.18397/kcgr.2014. 18.1.47

Chang, Y. R., Hong, J. H., \& Cha, J. H. (2012). A study on the factors which have influence on the performance and sustainability of social enterprises. Journal of Accounting and Finance, 30(2), 175-207.

Chaves, R., \& Monzón, J. L. (2011). Beyond the crisis: The social economy, prop of a new model of sustainable economic development. Service Business, 6(1), 5-26. https://doi.org/10.1007/s11628-011-0125-7

Choi, Y. C. (2013). A comparative analysis of the factors affecting successful operation of social enterprises: Application of FSQCA method. Korean Comparative Government Review, 17(1), 43-60. https://doi.org/10.18397/ kcgr.2013.17.1.43

Choi, Y. C., \& Lee, S. Y. (2015). Determinants affecting sustainability of social enterprises. Korean Comparative Government Review, 19(1), 157-178. https://doi.org/10.18397/kcgr.2015.19.1.157

Colbert, B. A., \& Kurucz, E. C. (2007). Three conceptions of triple bottom line business sustainability and the role for HRM. People and Strategy, 30(1), 21.

Collier, D. (2011). Understanding process tracing. PS, Political Science \& Politics, 44(4), 823-830. https://doi.org/10. $1017 /$ S1049096511001429

Collier, D., Brady, H. E., \& Seawright, J. (2010). Outdated views of qualitative methods: Time to move on. Political Analysis, 18(4), 506-513. https://doi.org/10.1093/pan/mpq022

Defourny, J., \& Nyssens, M. (2006). Social enterprise. In M. Nyssens (Ed.), Defining social enterprise (pp. 3-26). Routledge. 
Defourny, J., Develtere, P., \& Fonteneau, B. (1999). The social economy: The worldwide making of a third sector. HIVA, KULeuven.

Di Serio, L. C., de Oliveira, L. H., \& Schuch, L. M. S. (2011). Organizational risk management: A case study in companies that have won the Brazilian quantity award prize. Journal of Technology Management \& Innovation, 6 (2), 230-243. https://doi.org/10.4067/S0718-27242011000200016

Diochon, M., \& Anderson, A. R. (2011). Ambivalence and ambiguity in social enterprise: Narratives about values in reconciling purpose and practices. International Entrepreneurship and Management Journal, 7(1), 93-109. https:// doi.org/10.1007/s11365-010-0161-0

Gerring, J., \& Cojocaru, L. (2016). Selecting cases for intensive analysis: A diversity of goals and methods. Sociological Methods \& Research, 45(3), 392-423. https://doi.org/10.1177/0049124116631692

Hahn, S. J. (2014). Discourses of the social exclusion and social economic organizations in South Korea. Korean Regional Sociology, 15(2), 5-31.

Helmig, B., Ingerfurth, S., \& Pinz, A. (2014). Success and failure of nonprofit organizations: Theoretical foundations, empirical evidence, and future research. Voluntas: International Journal of Voluntary and Nonprofit Organizations, 25(6), 1509-1538. https://doi.org/10.1007/s11266-013-9402-5

Im, T., \& Cho, W. (2008). Decentralization and economic growth in Korea. Korean Journal of Policy Studies, 23(1), 49-71.

Ingelsson, P., Eriksson, M., \& Lilja, J. (2012). Can selecting the right values help TQM implementation? A case study about organisational homogeneity at the Walt Disney company. Total Quality Management \& Business Excellence, 23(1), 1-11. https://doi.org/10.1080/14783363.2011.637801

Kay, A., \& Baker, P. (2015). What can causal process tracing offer to policy studies? A review of the literature. Policy Studies Journal: The Journal of the Policy Studies Organization, 43(1), 1-21. https://doi.org/10.1111/psj.12092

Kim, C. H., Amaeshi, K., Harris, S., \& Suh, C. J. (2013). CSR and the national institutional context: The case of South Korea. Journal of Business Research, 66(12), 2581-2591. https://doi.org/10.1016/j.jbusres.2012.05.015

Kim, D., \& Cho, W. (2019). Cross-sector partnership in New Zealand local government: A case of affordable housing policy for older people in Auckland. The Korean Journal of Local Government Studies, 23(3), 115-134. https://doi. org/10.20484/klog.23.3.5

Kim, D., Cho, W., \& Park, H. (2019). Asset-building approaches to community development and the role of local government in urban regeneration. The Korean Journal of Public Administration, 28(3), 85-119.

Kim, D., \& Lee, S. (2008). The effect of trust in government on citizen participation. Korean Society and Public Administration, 18(4), 43-62.

Kim, D. K., \& Jeong, S. G. (2014). Improvement of social capital in Daejeon through social economy organizations: Focusing on the cases of Daejeon. Journal of Social Science, 25(1), 281-306. https://doi.org/10.16881/jss.2014.01.25.1.281

Kim, T. Y. (2012). Sustainability of social enterprise and sense of community. Journal of the Korean Urban Management Association, 25(3), 31-64.

Lee, E. S., \& Suk, H. W. (2016). A typology of SEOs in South Korea: Fuzzy ideal type analysis. Korean Society and Public Administration, 27(4), 179-213.

Lee, H. H., \& Li, M. F. (2015). Principal leadership and Its link to the development of a school's teacher culture and teaching effectiveness: A case study of an award-winning teaching team. International Journal of Education Policy and Leadership, 10(4), 1-17. https://doi.org/10.22230/ijepl.2015v10n4a555

Lee, H. J. (2019). The relationship between sustainability of social economy organization and cooperative network organization focused on central government, local government, and civic social organization. Social Economy \& Policy Studies, 9(1), 57-89. https://doi.org/10.22340/seps.2019.02.9.1.57

Lee, W. (2017). Sustainability of nonprofit human service organizations in a neighborhood context. Nonprofit Management \& Leadership, 28(1), 11-24. https://doi.org/10.1002/nml.21264

Lee, Y., \& Lee, M. (2017). The analysis of local community by network effect of social enterprises: Focusing on social venture valley in Seongsudong area. Journal of the Korean Regional Development Association, 29(2), $161-187$.

Leviton, L. C., Herrea, C., Pepper, S. K., Fishman, N., \& Racine, D. P. (2006). Faith in action: Capacity and sustainability of volunteer organizations. Evaluation and Program Planning, 29(2), 201-207. https://doi.org/10. 1016/j.evalprogplan.2006.01.011

Lofgren, K., \& Allen, B. (2019). In and out of amber: The New Zealand government major projects performance reporting. In D. Hodgson, M. Fred, S. Bailey, P. Hall (Eds.), The projectification of the public sector (pp. 95-111). Routledge.

López-Arceiz, F. J., Bellostas, A. J., \& Rivera-Torres, M. P. (2017). The Slaughtered and the survivors: Collaboration between social economy organizations as a key to success in times of financial crisis. Voluntas: International Journal of Voluntary and Nonprofit Organizations, 28(4), 1622-1647. https://doi.org/10.1007/s11266-017-9836-2

López-Arceiz, F. J., Bellostas Pérezgrueso, A. J., \& Rivera Torres, M. P. (2016). The effects of resources on social activity and economic performance in social economy organizations. Nonprofit Management \& Leadership, 26(4), 499-511. https://doi.org/10.1002/nml.21204

Mahoney, J. (2012). The logic of process tracing tests in the social sciences. Sociological Methods \& Research, 41(4), 570-597. https://doi.org/10.1177/0049124112437709 
Ministry of Government Administration and Home Affairs. (2016). 2016 guidelines for the promotion of community business.

Moizer, J., \& Tracey, P. (2010). Strategy making in social enterprise: The role of resource allocation and its effects on organizational sustainability. Systems Research and Behavioral Science, 27(3), 252-266. https://doi.org/10.1002/sres.1006

Moulaert, F., \& Ailenei, O. (2005). Social economy, third sector and solidarity relations: A conceptual synthesis from history to present. Urban Studies, 42(11), 2037-2053. https://doi.org/10.1080/00420980500279794

Noya, A. (2009). The changing boundaries of social enterprises. OECD.

Noya, A., \& Clarence, E. (2007). The social economy: Building inclusive economies. Publications de l'OCDE.

Oh, D. (2013). An exploratory study on leadership of social economy organization: A case study of social enterprise. Journal of Korean Social Welfare Administration, 15(4), 285-311.

Park, S., \& Um, T. (2010). Contradiction between social and economic aims of social enterprise and interaction effect of it's traditional social economic organization. Health and Social Welfare Review, 30(1), 287-311. https://doi.org/ 10.15709/hswr.2010.30.2.287

Pol, E., \& Ville, S. (2009). Social innovation: Buzz word or enduring term? The Journal of Socio-economics, 38(6), 878-885. https://doi.org/10.1016/j.socec.2009.02.011

Powell, M., Gillett, A., \& Doherty, B. (2019). Sustainability in social enterprise: Hybrid organizing in public services. Public Management Review, 21(2), 159-186. https://doi.org/10.1080/14719037.2018.1438504

Prieto, L. C., Phipps, S. T. A., \& Addae, I. Y. (2014). Is Wal-Mart a social enterprise? An exploration of the relationship between corporate reputation, corporate social responsibility \& financial performance. Academy of Strategic Management Journal, 13(2), 51.

Rutzen, D., Durham, M., \& Moore, D. (2004). Overview of NPO legislation in central and east europe. (Online), 19 August 2018.

Sharir, M., \& Lerner, M. (2006). Gauging the success of social ventures initiated by individual social entrepreneurs. Journal of World Business, 41(1), 6-20. https://doi.org/10.1016/j.jwb.2005.09.004

Song, W.-C. (2017). The exploratory study on the innovation behaviour of social economy. Innovation Studies, 12(2), 1-26. https://doi.org/10.46251/INNOS.2017.05.12.2.1

Spall, P., \& Zetlin, D. (2004). Third sector in transition: A question of sustainability for community service organizations and the sector? Australian Journal of Social Issues, 39(3), 283-298. https://doi.org/10.1002/j.1839-4655.2004. tb01177.x

Thompson, J., \& Doherty, B. (2006). The diverse world of social enterprise: A collection of social enterprise stories. International Journal of Social Economics, 33(5/6), 361-375. https://doi.org/10.1108/03068290610660643

Van Evera, S. (1997). What are case studies? How should they be performed. In Van Evera, S. (Ed.) Guide to methods for students of political science (pp. 48-88). Cornell University Press.

Virakul, B., Koonmee, K., \& McLean, G. N. (2009). CSR activities in award-winning Thai companies. Social Responsibility, Journalism, Law, Medicine, 5(2), 178-199. https://doi.org/10.1108/17471110910964478

Visser, M. A. (2017). A floor to exploitation? Social economy organizations at the edge of a restructuring economy. Work, Employment and Society, 31(5), 782-799. https://doi.org/10.1177/0950017016638020

Wahl-Jorgensen, K. (2013). The strategic ritual of emotionality: A case study of pulitzer prize-winning articles. Journalism, 14(1), 129-145. https://doi.org/10.1177/1464884912448918

Wales, T. (2013). Organizational sustainability: What is it, and why does it matter. Review of Enterprise and Management Studies, 1(1), 38-49.

Weerawardena, J., McDonald, R. E., \& Mort, G. S. (2009). Sustainability of nonprofit organizations: An empirical investigation. Journal of World Business, 45(4), 346-356. https://doi.org/10.1016/j.jwb.2009.08.004

Weppen, J., \& Cochrane, J. (2012). Social enterprises in tourism: An exploratory study of operational models and success factors. Journal of Sustainable Tourism, 20(3), 497-511. https://doi.org/10.1080/09669582.2012.663377

Wheeler, D., McKague, K., \& Thomson, J. (2003). Sustainable livelihood and the private sector: How development agencies can strengthen sustainable local enterprise networks, final report. School of Business, New York University.

Wilburn, K., \& Wilburn, R. (2014). The double bottom line: Profit and social benefit. Business Horizons, 57(1), 11-20. https://doi.org/10.1016/j.bushor.2013.10.001

Windrum, P., Schartinger, D., Rubalcaba, L., Gallouj, F., \& Toivonen, M. (2016). The co-creation of multi-agent social innovations. European Journal of Innovation Management, 19(2), 150-166. https://doi.org/10.1108/EJIM-05-20150033

Yin, R. K. (2012). A (very) brief refresher on the case study method. Applications of Case Study Research, 3. SAGE Publications, Inc.

Young, D. R., \& Lecy, J. D. (2014). Defining the universe of social enterprise: Competing metaphors. Voluntas, 25(5), 1307-1332. https://doi.org/10.1007/s11266-013-9396-Z 